\section{ТУВИНСКОЕ ВРЕМЯ И ЭКОНОМИЧЕСКАЯ КУЛЬТУРА ТУВИНЦЕВ}

\author{
Чимиза К. Ламажаа \\ Московский гуманитарный \\ университет, Российская Федерация
}

\section{“TUVAN TIME" AND ECONOMIC CULTURE OF TUVANS}

\author{
Chimiza K. Lamazhaa \\ Moscow University for the Humanities, \\ Russian Federation
}

\begin{abstract}
В статье впервые анализируется тувинское время (тыва үе) - понимание тувинцами повседневного времени, как важная часть их общей культуры, имеющая тесную взаимосвязь с экономической культурой. Подобное отношение ко времени у тувинцев рассматривается как степное время, которое наблюдается также у народов Монголии, и других регионов кочевой культуры центральной Азии. Люди степи демонстрируют особое время культуры, особый темп жизненного уклада, который относится исследователями к варианту восточного типа понимания времени.

Отмечается, что для понимания времени традиционно использовались средства опредмечивания, соотнесения с конкретными действиями и обозначением места действий. Рассматриваются термины тувинского языка, означающие время. Фиксируются интересные выводы других исследователей (филологов, культурологов) об особенностях ориентации тувинцами во времени и пространстве, которые опираются на наблюдения за движением Солниа, звезд.

Особо акцентируется проблема обусловленности тувинского времени и экономической культурой
\end{abstract}

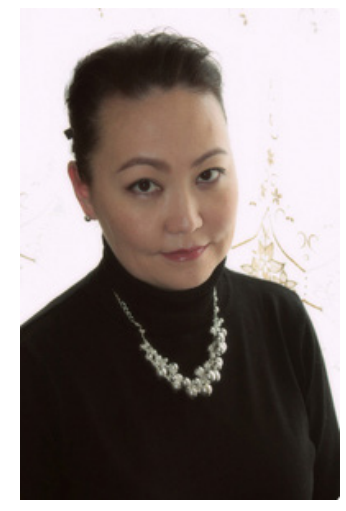

This is a first ever study of the notion of 'Tuvan time' (Tyva ye) - the way Tuvans reckon time in their everyday lives. This idea is examined as an integral part of Tuvan culture, being most directly linked to practices of economic culture. This vision of time can be seen as a version of 'steppe time', also typical for the peoples of Mongolia and other Central Asian regions of nomadic culture. People of the steppes have been found to possess a specific cultural time, a certain pace of lifestyle which has been classified within the Oriental type of understanding time.

To reckon and understand the notion of time, Tuvans have traditionally used the strategies of objectification, matching time to specific action and mentioning the place of action. The article studies Tuvan terms signifying time, with a focus on the conclusions scholars of language and culture have made in their studies of how Tuvans find their way in space and time by observing the daily motion of the Sun and stars.

Special attention is given in the article to the link between 'Tuvan time' and their economic culture. This way of understanding time appeared in the economic lifestyle of extensive animal farming that most Tuvans in the past and present were involved in.

Ламажаа Чимиза Кудер-ооловна - доктор философских наук, заместитель директора по научной работе Института фундаментальных и прикладных исследований Московского гуманитарного университета. Адрес: 111395, Россия, г. Москва, ул. Юности, д. 5, корп. 6, каб. 18. Тел.: +7 (499) 374-73-90. Эл. адрес: lamajaa@tuva.asia

Lamazhaa Chimiza Kuder-oolovna, Doctor of Philosophy, Deputy Director, Institute of Fundamental and Applied Studies, Moscow University for the Humanities. Postal address: 5 Yunosti St., Moscow, Russian Federation, 111395. Tel.: +7 (499) 374-73-90.E-mail: lamajaa@tuva.asia 
тувинцев. Понимание времени сложилось в условиях экстенсивного скотоводства, которым занималось большинство предков и современных тувинцев. Соответственно хозяйственная деятельность людей почти целиком зависела от природных, погодных циклов, ритмов, конкретных условий. Это обусловило стратегию адаптации не только к собственно среде, но и к протеканию процессов в этой среде, $к$ самому пониманию времени. Человеку оставалось только следить за неспешным процессом выпаса скота и отчасти его регулировать. Это определило неспешность как одну из главных временных характеристик культуры.

Анализируются культурные установки тувинцев, связанные с планированием и пунктуальностью. В постсоветское время тыва үе подчеркивается как право людей не соблюдать точное время. Тыва үе определяется не как время, а как комплекс обстоятельств (изменение погоды, приметы, необходимость соблюдения важных дел, получение указаний от кого-либо), которые сильнее людей и которые влияют на их намерения, на длительность событий, действий. Неспешность особенно заметна у жителей сельских районов, но присутствует и у горожан из-за значительной внутренней миграции в Туве из села в город, а также в силу устойчивости базисных оснований традиционной культуры в ситуации «вписывания» ее носителей в современность.

Фактор тувинского времени следует учитывать приезжим, самим жителям Тувы, органам власти, представителям бизнеса как существенный фактор современной экономической культуры тувинцев и важное условие стратегического планирования.

Ключевые слова: время; категория времени; тувинское время; степное время; кочевая культура; пунктуальность; планирование; тувинцы; Тува; экономическая культура
Correspondingly, their economic activity almost wholly depended on natural cycles, weather changes, climatic rhythms and conditions. This determined the strategy of adapting to both the environment in general and to its elements, such as the flow of events and of time in this environment. People had only to watch the slow grazing of their cattle and only at times intervene to regulate the process. This made unhurriedness one of the most important temporal features of Tuvan culture.

The article analyzes the cultural views of the Tuvans on planning and punctuality. In the post-Soviet years, 'Tyva ye' has come to mean the right to be imprecise and is determined by several circumstances, such as a change in weather, climate lore, the need to follow important routines or directions. All of these factors are seen as bigger and more important than people, control their intentions and regulate the length of events and actions. Unhurriedness is most marked among the rural populations, but is also quite conspicuous in urban areas since internal migration from the countryside to towns remains significant. Foundations of traditional culture remain strong, too, since those who feel bound to it have managed to "write it into" their contemporary lives.

The factor of 'Tuvan time' is an important one to reckon for visitors to the region, residents of Tuva, local authorities, business people. It is an important element of contemporary economic culture and a powerful precondition for strategic planning.

Keywords: time; category of time; 'Tuvan time'; time of the steppes; nomadic culture; punctuality; planning; Tuvans; Tuva; economic culture

\section{Введение}

Понимание категории времени в кочевых культурах относится исследователями к общей модели восточной культуры и в целом противопоставляется представлениям западной культуры. Разница в культурных установках настолько существенная, что становится сразу очевидной при встрече представителей двух культурных миров. Так, люди западного мышления, привыкшие ценить точность, пунктуальность, приехав в степные районы и столкнувшись с иным пониманием времени у кочевников, теряются и испытывают дискомфорт. Сами местные жители также оказываются в ситуации встречи культур, наблюдая в приезжих людей торопливых, суетящихся.

Однако, помимо этих повседневных проблем, современные условия глобализации поставили перед людьми разных культур задачи и экономического диалога - раз- 
вития собственной экономики, приспособления своей деятельности к общим рыночным условиям. Но задачи эти корректируются со спецификой экономической культуры - трудовой мотивации, особенностей сознания и поведения, основанных на традиционных видах хозяйственной деятельности. И одним из аспектов экономического сознания является понимание времени, исчисление времени, которое имеет значительное влияние на скорость принятие решений, на темп работы, пунктуальность и пр.

Целью настоящей работы является анализ понимания времени в тувинской культуре, не мифологического времени, не исторического, а повседневного, которое рассматривается в тесной взаимосвязи с экономической культурой тувинцев. Тема эта является чрезвычайно важной в связи с обсуждением особенностей экономической культуры тувинцев, в свете перспектив экономического развития Тувы, и в целом регионов, население которых преимущественно является потомками кочевников.

\section{Степное время и столкновение культур}

«Тувинское время» или тыва уе - идиома, распространившаяся в постсоветское время в Туве, выражающая неспешность тувинцев, их ориентацию не на циферблат, а на некие внешние факторы, которые побуждают действовать (природные явления, указания от кого-либо), а также невозмутимость в ситуации принятия решений.

Эта относительная неспешность и тувинцев, и монголов, и других народов кочевой культуры уже достаточно описана в научной литературе как одна из особенностей пространственно-временной картины мира. В целом подобное отношение ко времени у кочевников можно назвать степным временем, которое до сих пор удивляет приезжих в Туве, в Монголии, других регионах.

Например, монголовед, дипломат, историк, публицист М. И. Майский, в начале $\mathrm{XX}$ века работавший в Монголии, писал, что известную пословицу «Время - деньги» в монгольской степи следует «вывернуть наизнанку»: «Время - не деньги». Ситуацию, которая привела его к такому выводу, он описывал так:

«Если вы уславливались с монголом о выходе каравана в пятницу, вы могли быть уверены, что он приведет верблюдов только в воскресенье или в понедельник. И если вы обрушивались на опоздавшего с упреками, он с самым невозмутимым видом заявлял:

- А я думал, что ты в этот день не поедешь.

- Как не поеду, как у нас было условлено выступать именно в этот день?

- Да я посмотрел с утра - погода будто плохая, облака на небе... Я и подумал, что ты не поедешь... Куда торопиться? Дней в году много...» (Майский, 1959: 47).

Наблюдая за монголами, автор признавал, что это не пустые отговорки, а вполне искреннее убеждение. «Он (монгол. - Ч. Л.) просто органически не в силах был понять, как можно придавать значение выходу каравана в определенный день, потому что дней в году действительно много и все они для него совершенно равны» (там же). 
В одной из полевых записей во время поездки в Монголию в 1988 г. Н. Л. Жуковская упоминает о 9-дневном ожидании учеными поездки из Улан-Батора в поле. Сначала у них не было ни денег, ни машины, ни бензина, ни сопровождающего. Но даже при появлении транспортного средства и заправки, выехать долгое время никак не удавалось: сначала один сопровождающий монгол не мог поехать (так как у него три дня назад родилась дочь), затем монголка, которая его заменила, не могла по разным причинам (то сложно собраться, то надо куда-то съездить, то просто несчастливый день)... (Жуковская, 2002: 52-52).

Схожую историю про недавние приключения германских журналистов в Туве я слышала в 2017 г. из уст этномузыковеда В. Ю. Сузукей ${ }^{1}$. Дисциплинированные и пунктуальные планировщики своего путешествия вооружились картами, навигаторами, выстроили хронометраж поездки от столицы республики до районного центра и отметили точный час, чтобы успеть выехать и прибыть на место, встретиться с нужными им людьми - героями своего проекта. И договорились с местным водителем об отправлении автобуса в 8 утра... Когда он появился в 11 часов, в ответ на гневные отповеди уже взвинченных ожиданием путешественников, он лишь пожал плечами «Мне жена пирожки в дорогу пекла». Удивился, зачем надо так торопиться. И обещал привезти их к месту вовремя. Однако, надо сказать, во время поездки немцам пришлось самим несколько раз просить остановить машину, чтобы запечатлеть на фото- и видеоаппаратуру на перевалах природные красоты, от которых у них захватывало дух.

Монгольский ученый Х. Цооху пишет, что для монголов любимым словом является маргаш - завтра. Он эквивалентен словосочетанию «через 24 часа», но в действительности, к сожалению, может означать и несколько дней, даже недели. «В чем причина такого неудобного положения? - размышляет автор. - Монгол не может детально рассматривать суть задания или обязанности, он подходит к нему на основе душевной ориентации и допускает ошибку в распределении времени. Поэтому обещание “завтра” часто не выполняется вовремя» (Монгольский мир ..., 2014: 167).

После столкновения с такими примерами «природной распущенности», как называет это Х. Цооху (там же), после первого культурного шока и погружения в неспешный стиль жизни аборигенов люди западной цивилизации обычно начинают осознавать, что им проще оставить свои привычки, свою пунктуальность, чем пытаться добиться от местных жителей понимания и такой же заботы о быстро утекающих часах и минутах. Степное восприятие времени не связано с секундами, с минутами. Люди степи не распоряжаются временем, а приспосабливаются к нему, тем самым демонстрируя особое время культуры, особый темп жизненного уклада (Бортникова, 2017: 28).

\section{Научные подходы к тувинскому времени}

Проблема культурных оснований для формирования стратегий экономической деятельности является новой для тувиноведения, а также других прикладных

Благодарю Валентину Юрьевну Сузукей за любезное согласие изложить эту историю в статье. 
научных отраслей, комплексно изучающих конкретные этнические культуры центральноазиатского региона. Прежде всего это было связано с тем, что регион входил в советское пространство, где эта тема, как мы понимаем, не была востребована и исследования культуры, культурных факторов имели свои особенности, в зависимости от особенностей исторического развития науки и социальных условий.

Достаточно долгое время в тувиноведении (Ламажаa, 2010: Электр. ресурс) доминировал этнографический подход к тувинской этнической культуре в целом, и к экономической культуре в частности, направленный прежде всего на фиксацию, систематизацию этнографического материала. В его рамках проблема основных мировоззренческих категорий, в том числе категорий пространства и времени, рассматривается в основном как особенности этнической - тувинской - картины миры. Вопросы экономической культуры, где главными основными терминами являлись термины «хозяйственная деятельность», «культурно-хозяйственный тип» и пр. исследовались обычно отдельно. Разумеется, исследователи понимали тесную взаимосвязь мировоззрения и деятельности, однако, трактовали ее часто в рамках своих теоретических парадигм, которые при всех попытках объективного анализа имеющихся фактов, в свою очередь строились на основе определенных социальных, идеологических заказов.

Так, например, в одной из часто цитируемых этнографических работ по традиционной культуре тувинцев Л. П. Потапова «Очерки народного быта тувинцев» (Потапов, 1969), теме понимания времени тувинцами отведен отдельный раздел. Автор использует здесь термин «народные знания», противопоставляя их научным знаниям о природе, то есть фактически относя народные знания к ненаучным, точнее - до научным: «... в этих народных знаниях и представлениях часто встречаются иррациональные элементы» (там же: 279). Это было вполне в духе представлений о прогрессивном характере развития знаний и деятельности XX века. Однако, этнограф признает: «... тем не менее в своей массе они вполне рациональны и заслуживают положительной оценки, так как в свое время влияли на развитие и уровень жизни народа» (там же).

К народным знаниям Л. П. Потапов относит летоисчисления, приводя полученные им в полевых исследованиях сведения о календарях тувинцев: 12-летнем животном цикле, годовом календаре. Автор подробно приводит описания представлений тувинцев о каждом годе и каждом месяце, поскольку они были связаны с различными поверьями и приметами: «С каждым годом двенадцатилетнего цикла были связаны представления о счастливом и несчастливом годе, причем критерием для такой характеристики являлась главным образом погода и ее влияние на хозяйство» (там же: 282). Так, например, Год мыши считался «счастливым», т. к. снега бывает мало, скот хорошо зимует, охота на зверя добычлива, посев дает хороший урожай, люди живут хорошо (там же: 282-283). Засушливым считался Год змеи, несчастливыми - Год обезьяны, Год курицы и др. Характеристики месяцев у тувинцев также связывались с определенными хозяйственными занятиями. При этом, начальным зимним месяцем считался нынешний декабрь. Аалы в этот месяц уже находились на зимних стойбищах, утеплялись зимние загоны для скота, охотники выходили или уже находились на промысле (там же: 284-285). 
Л.П.Потапов не углубляется в вопрос о происхождении у тувинцев 12-летнего цикла, отмечая лишь распространенность этой системы у многих народов центральной Азии и очевидное удобство при исчислении личного возраста человека, «так как считать по этому календарю было не трудно любому неграмотному человеку, ввиду того, что названия двенадцати животных, именами которых обозначали названия лет данного цикла, шли одно за другим в одном и том же порядке. Родившийся, например, в год мыши вел счет своему возрасту с этого года, и его рождение приходилось по данному календарю через каждые 12 лет, считая с года мыши. Зная, сколько раз в течение его жизни наступал год мыши, человек точно определял свой возраст, он складывал двенадцатилетия и прибавлял к ним годы, прошедшие от последнего года мыши» (там же: 287). Подобное заключение о неграмотности и одновременно способностях складывать и прибавлять точные цифры, конечно, несколько противоречиво.

Главным же фактом является то, что для тувинцев не был актуальным вопрос об установлении точного астрономического возраста. В многочисленных исследованиях проблематики возраста у тувинцев, обрядов жизненного цикла присутствуют прежде всего общие названия, термины для возрастных категорий, и нет точных указаний на количество лет (например: Кенин-Лопсан, 2006: 4-5; Волков, Салчак, Шаалы, 2009; Айыжы, 2015). Авторы монографии по педагогическим традициям тувинцев Г. Н. Волков, К. Б. Салчак и А. С. Шаалы, пишут, что «В обычной жизни возраст человека тувинцы делят на три этапа:утро жизни - детство (чаш, бичии уе); полдень - зрелость (улуг кижи); вечер - старость (кырган назын). Такое представление отражено в тувинском фольклоре, в частности, имеется загадка: “Утром на четвереньках, в полдень на двух ногах, а вечером - на трех” (Волков, Салчак, Шаалы, 2009: 40).

Современные исследования происхождения 12-летнего животного цикла у народов Юго-Восточной Азии предлагают разные гипотезы по вопросу истоков появления такого исчисления, но и особенности его распространения и развития до 60-летних циклов. Так, согласно астрономической гипотезе, действующий уже несколько тысяч лет в регионахАзии (Центральной и Юго-Восточной) 60-летний циклический календарь представляет собой хронологическую систему, основанную на астрономических циклах движения Солнца, Земли, Луны, Юпитера и Сатурна (Цимбульский, 1982: 78; Монгуш, 2015: Электр. ресурс). Об отличном врожденном зрении кочевников и их умении наблюдать прохождение по небу звезд, в том числе Юпитера писали путешественники еще XIX века, например, Ф. П. Врангель (Путешествие ... , 1948). В. В. Цимбульский предположил, что эта наблюдательность кочевников и позволила им установить время, за которое Юпитер делает полный оборот вокруг Солнца примерно за 12 лет. Разделив путь Юпитера на 12 равных частей по 30 и дав каждой части наименование определенного животного, кочевники Центральной Азии создали солнечно-юпитерный 12 летний календарный цикл (Цыбульский, 1982: 78-79). Он также пишет, что семья кочевника имела свою юрту, купол которой в теплую часть года оставался открытым, а жерди купола служили ориентиром для наблюдения звезд и планет, что делало юрту была своеобразным семейным «планетарием», благодаря чему накапливались астрономические знания и передавались из поколения в поколение. Развитие же календаря с 12-летним циклом до 60-летнего, по мнению ряда авторов, принадлежит китайцам (Яковлев, Электр. ресурс). 
Н. Л. Жуковская также упоминает разные гипотезы относительно происхождения 12-летнего календаря и отмечает относительно большую ясность с астрономической гипотезой: «Астрономической основой 12-летнего календаря может быть только вычисленный астрономами еще в глубокой древности “юпитерный” цикл, т. е. период полного оборота Юпитера вокруг Солнца, равный 12 годам, а если быть совсем точным - 11,862 года» (Жуковская, 2002: 57).

Очевидно, что исследования народных знаний тувинцев (как и других кочевых народов) относительно пространственно-временных категорий нуждаются в углублении, а также в применении междисциплинарного подхода. Традиционное понимание времени народами имеет глубокие корни и представляет собой не просто комплекс знаний, точных наблюдений за природными явлениями, но и комплекс знаний в сочетании с их применением в хозяйственной деятельности.

Тема интерпретации народным сознанием десятков поколений природных явлений, их происхождения, соответствующих им процессов, которая происходила в форме мифологизации (Традиционное мировоззрение..., 1988), в этом случае является отдельной темой, связанной с мифологическим временем культуры. Углубленные исследования повседневного понимания времени помогут рассматривать рациональные основания традиционной культуры.

\section{Отночение ко времени как элемент культуры}

Современная наука в основном отошла от прогрессистского отношения $\mathrm{k}$ ценностям разных культур и уже не расценивает их с точки зрения правильности или не правильности, близости к абсолютной истине. Научную трактовку картины мира культур, приближение к пониманию тувинского времени необходимо производить, оставив оценочные суждения и предубеждения, принимая культурную обусловленность как объективную социокультурную данность.

Как подчеркивает английский лингвист Р. Льюис, «картина мира меняется от одного языка к другому, и деловое поведение меняется вслед за ней. Не существует однойединственной метафизической сферы человеческих мыслей и действий. Различным языкам соответствуют различные “сегменты опыта", и нам не остается ничего другого, кроме как изучать больше языков» (Льюис, 1999: 52).

Вопрос об отношении ко времени, имеющем культурную специфику, ныне в условиях глобализации активно обсуждается в культурологической литературе, востребованной для бизнеса, то есть имеющей практическую направленность. Среди концепций специалистов по межкультурным коммуникациям, компаративистским работам известны типологии культур в зависимости от отношения ко времени.

Так, интересна типология активности культур уже упомянутого Р. Льюиса моноактивные (Linear-active), полиактивные (Multi-active) и реактивные (Reactive) (Lewis, 2006). Для первых важны пунктуальность, исполнительность; выполнение задачи - превыше всего (американцы, англичане, немцы, швейцарцы, шведы, датчане и др.) Вторые отличаются эмоциональностью своих представителей, гибкостью их поведения; их не очень заботит пунктуальность, они привыкли делать множество дел 
одновременно, нередко не доводя их до конца (итальянцы, латиноамериканцы, арабы и др.). Реактивные (слушающие) культуры придают наибольшее значение вежливости и уважению (жители Японии, Китая, Тайваня, Сингапура, Кореи), сохранению репутации. Они организуют свою деятельность не по строгому и неизменному плану, а в зависимости от обстоятельств, реагируя на происходящие изменения.

Еще одна известная концепция принадлежит перу американского антрополога Э. Холла. Он подразделил культуры в зависимости от характера использования ими пространства и времени на высококонтекстные и низкоконтекстные, а также культуры с преобладающим монохромным или полихромным использованием времени (Hall, 1966, 1976). Представители монохромных культур стремятся четко расписывать свой график и заниматься делами последовательно, приступать к выполнению новой задачи только после выполнения предыдущей. В этих культурах межличностные отношения менее важны, чем выполнение задачи - по крайней мере, в деловой сфере (США, Англию, Германию, Скандинавские страны). Представители полихромных культур чаще занимаются множеством дел одновременно, четких графиков они не составляют или, по крайней мере, не слишком охотно их придерживаются (культуры латиноамериканских и арабских стран, а также Россия) (Hall, 1966).

Определенные выводы исследователей представляют интерес для нашей темы и в следующем отношении. В концепции Р. Льюиса, например, упоминается такая особенность некоторых восточных культур, в которой единственно возможным отношением ко времени признается адаптация людей к нему. В этих культурах время не линейно, но и не привязано к людям или событиям, оно циклично. Каждый день солнце встает и садится, одно время года следует за другим, небесные тела совершают свое круговращение, люди стареют и умирают, но их дети повторяют все сначала. И поскольку многие жители Азии хорошо знают о циклической природе времени,деловые решения принимаются там совершенно иначе, чем на Западе. Западный человек часто ждет от восточного быстрого решения или такого подхода к текущей сделке, который основан на ее сегодняшних преимуществах и не учитывает того, что было в прошлом. Но восточный человек так поступать не может. Прошлое создает контекст, подоплеку настоящего решения, которое они, как восточные люди, могут долго обдумывать - их руки связаны самыми различными обстоятельствами (Льюис, 1999: 94).

Так, в культурологии признано, что каждая культура имеет свое собственное понимание времени, которое необходимо знать и понимать, и понимание времени определяет темп жизненного уклада, особенности протекания коммуникации людей (Бортникова, 2017: 28).

\section{Опредмечивание тувинского времени}

Отсутствие четких, акцентированных временных отрезков, которые бы измерялись приборами и понимались в абстрактном, числовом измерении, архаическими культурами восполняется с помощью мифологизации, а также опредмечивания, соотнесения с конкретными действиями и обозначением места действий. На этом основании сложились и традиции культуры кочевников (Кононов, 1978). 
Например, исследователи монгольской культуры пишут о том, что в зачинах эпических произведений народов время первотворения мира выражается через фразы действий, при этом формула времени заменена картиной мира (Скородумова, 2004: 229; Пространство в традиционной ... , 2008: 36). Выразителями наступления времени, его протекания, изменения становятся небесные светила, атмосферные явления, растения, животные.

В древних текстах тувинского эпоса тоже используются именно эти маркеры. Формулировки обозначения собственно времени, термины тувинского языка шаг (время), шагда (давно), которые можно увидеть в опубликованных ныне изданиях тувинского фольклора, часто являются привнесенными элементами, словамиклише современных сказителей-информантов (см.: Ондар, 2017). В ранних пластах фольклора распространены формулы обозначения времени в соотнесении с временем суток (утро, ночь), сменой сезонов года, действиями героев.

Хорошо известен этнографами бытовой способ определения дневного времени кочевниками - по движению солнечного луча, падающего сквозь дымовое отверстие и передвигающегося по внутренней обстановке юрты (Потапов, 1969: 298-299, 301-304; Жуковская, 2002: 40). Другие способы увязывались с различными бытовыми действиям: время заваривания чая, время кипячения молока в котле, время выкуривания одной трубки и др. (Потапов, 1969: 305).

Еще один аспект опредмечивания времени до сих пор выражается в тувинском языке, присутствует в терминологии пространственно-временных координат, о чем интересно пишет В. Ю. Сузукей (Сузукей, 2009: Электр. ресурс). Так, знание народа о пространстве и времени соотносилось не только с видимым (с поверхности Земли) движением Солнца, но и учитывало движение планет Солнечной системы в масштабах Галактики. Юг в тувинском языке обозначается словосочетанием мурнуу чүк - «передняя сторона» (Тувинско-русский словарь ..., 1968: 304), т. е. сторона света, находящаяся спереди или в передней части. Причем эта ориентация, по мнению Сузукей, была аналогичной положению человека, который находился лицом к теплу, как перед костром, наблюдал за прохождением Солнца по экватору. Соответственно юг становился «верхним миром». А север - соңгу чүк (задняя сторона) (там же: 382) рассматривался как «нижний мир», холодный, поскольку человек располагался к нему спиной. Соответственно, «восток» и «запад» также меняют направления или местоположение относительно правой и левой руки человека (Сузукей, 2009, Электр. ресурс).

Ориентация во времени также опирается на наблюдения о движении солнца. Собственно слово хүн имеет два значения: «день» и «Солнце». Чередование дней во времени имеет следующие обозначения:

\begin{tabular}{|c|c|}
\hline ПРОШЛОЕ & БУДУЩЕE \\
\hline дүүн-вчера & даарта - завтра \\
\hline бурунгу хүн-позавчера & соңгузу хүн - послезавтра \\
\hline бурундаа хүн-поза-позавчера & соондаа хүн - послепослезавтра \\
\hline
\end{tabular}

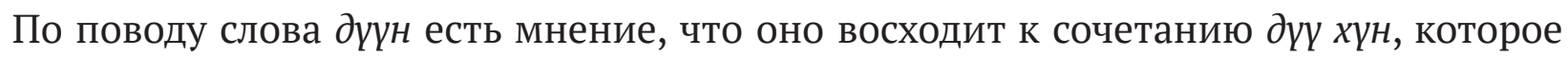
переводится как «тот день» и относится к указанию на объект (см.: Татаринцев, 2002: 
302, 237) - очевидно, может иметь и трактовку «то Солнце». А словосочетание буруңгу хүн расшифровывается, как день, прошедший впереди вчерашнего дня, т. е. слово «впереди» соотносится с ориентацией человека, смотрящего вперед. Соответственно бурундаа хүн означает день, прошедший раньше или вперед позавчерашнего дня. Слово буруңгаар в тувинском языке означает движение «вперед» и показывает на позицию впереди человека. В. Ю. Сузукей эту логику трактует так: в реальной жизни «прошлое» действительно проходит «перед глазами» человека и все события прошедшего времени, как правило, известны человеку во всех деталях.

Логика понимания будущего выстраивается соответственно в противоположном порядке. Слово даарта образовано путем сращения слов в сочетании даң эрте (раньше первых лучей солнца, раньше зари) (Татаринцев, 2002: 28, 85). Соңгузу хүн означает день, который придет после завтрашнего дня или день идущий сзади завтрашнего дня. Соондаа хүн - день, грядущий или идущий позади послезавтрашнего дня.

Таким образом, названия дней в прошедшем времени обозначены как дни, ушедшие вперед. События дней будущего времени «надвигаются» на человека сзади и он еще не знает, какие события будут происходить в будущем, поскольку они находятся у него «за спиной» (там же).

В. Ю. Сузукей подчеркивает, что «описание» времени и пространства в тувинском языке учитывает глобальное движение планет Солнечной системы в масштабах Галактики (и, возможно, Метагалактики) (там же). Подобная солнечная ориентация является традиционной для многих тюркских народов (Кононов, 1978).

Понимание тувинского времени также основано на разном подходе к вопросу чисел и исчислений, который отражен в языке, а значит - в ментальных установках, в логике мышления. Интерес представляют тезисы В. Ю. Сузукей относительно понимания математических дробных чисел в тувинском языке. Так, в тувинском языке, например, они прежде всего произносятся «снизу верх» (от целого числа к частному, а в русском языке часто наоборот - от частного к целому. Для тувинцев, например, такое озвучивание времени, как «половина второго» требует некоторого времени для переосмысления этой фразы на тувинское звучание (поскольку на тувинском языке будет строиться в ином порядке - как «Один час с половиной», Бир шак чартык), иначе он придет на свидание на один час позже (или опоздает на поезд или самолет) (Сузукей, 2009: Электр. ресурс).

Так, повседневное тувинское время является составной частью картины мира культуры, выражается особой логикой тувинского языка и соответственно должно рассматриваться как ментальная установка.

\section{Хозяйственно-экономическая обусловленность формирования тувинского времени}

Как я уже упоминала, исследования пространственно-временных представлений тувинцев и особенностей их хозяйственной деятельности, по традиции производились отдельно. Это, конечно, не было особенностью тувиноведения. Подобный подход 
был общим в научном знании, когда экономисты настороженно относились к такой «расплывчатой» теме, как культура, а культурологи, философы в свою очередь были критически настроены к экономике (см.: Безуглова, 2015).

Сегодня тематика взаимосвязи культуры с экономикой и собственно экономической культурой - стала очень актуальной, востребованной и обсуждается в самых разных аспектах. При этом исследования экономической культуры активно проводятся как философами, так и самими экономистами. Культура имеет значение для экономики (Культура имеет ... , 2002) и это утверждение уже мало кем оспаривается. Исследовательские интересы сейчас сконцентрированы на решении вопросов о том, каким является это значение, как оно проявляется, как его исследовать (Sen, 2004).

«Культурный поворот» (cultural tern) в проблематике экономики Тувы произошел и в тувиноведении с середины 1990-х гг. - прежде всего с работ Г. Ф. Балакиной и 3. В.Анайбан (Балакина, Анайбан, 1995). Однако, при анализе экономической культуры тувинцев тема отношения ко времени ими практически не поднималась.

Чтобы говорить о соотношении этих двух понятий, прежде всего, уточню основное определение. Экономическая культура рассматривается мною как составная часть культуры, как совокупность ценностей, норм, стереотипов, определяющих особенности хозяйственной деятельности людей. Соответственно, экономическая культура, как и вся культура, имеет особый временной аспект - мифологическое время, историческое, повседневное. Особое понимание времени сложилось в ходе практического освоения мира, в ходе хозяйственной деятельности, выражено в языке, влияет на особенности планирования дел, их реализацию, проявляется в скорости и обстоятельствах принятии решений. То есть необходимо говорить о сложном переплетении, взаимовлиянии экономической культуры и тувинского времени.

Главным видом занятий тувинцев было разведение животных в форме экстенсивного пастбищного скотоводства, когда скот выпасался на естественных пастбищах, которые менялись в зависимости от сезонов года. Соответственно хозяйственная деятельность людей почти целиком зависела от природных, погодных условий. Это обусловило стратегиюадаптации нетолько ксреде,нои кпротеканиюпроцессов в этойсреде, ксамому пониманию времени. А поскольку человеку оставалось только следить за неспешным процессом выпаса скота и отчасти его регулировать, то это определило неспешность как одну из главных временных характеристик культуры. С этой неспешностью тесно связан и фатализм, предопределенность понимания происходящего в жизни, поскольку значительным природным явлениям, в том числе стихийным бедствиям, эпидемиям скота - человек не был в силах противостоять. Смены сезонов, природные циклы, повторяющие траектории небесных тел - все это обусловило понимание глобального порядка, которое следовало принимать как данность.

Сегодня основная часть тувинского этноса - сельчане - традиционно являются выразителями и носителями основного хозяйственно-культурного типа кочевых скотоводов (Вайнштейн, 1972), поэтому столь живо и тувинское время - степное время, или время скотоводов. Разумеется, помимо основного хозяйственнокультурного типа (ХКТ) кочевых скотоводов, в Туве были распространены и ХКТ земледельцев, охотников, оленеводов, о которых писал С. И. Вайнштейн (там же). 
Особенности их деятельности, их стратегий действий и освоения пространства и времени существенно разнообразят тувинскую картину мира и добавляют к ней и представления о человеческой активности и динамизме событий, которые зависят и от действий самих людей.

\section{Риверсивность тувинского времени и экономической культуры}

Связь времени и экономической культуры - не одностороннее движение. Эта связь характеризуется и обратным воздействием времени на экономическую культуру, т. е. риверсивностью (обратимостью, возвратностью). В настоящее же время экономическая культура тувинцев, как уже подчеркивалось, в существенной мере определяется фактором тыва үе. Он также присутствует и в городской жизни республики благодаря значительной внутренней миграции - из села в город.

В последние годы mыва үе даже подчеркивается в общественном дискурсе как право людей на задержки, на опоздания; как оправдание нелюбви тувинцев к пунктуальности. Концепт тыва үе выражает, прежде всего, не само время, а комплекс обстоятельств, которые во многом определяют мотивацию и деятельность людей, которые влияют на длительность событий, протяженность действий, на определение момента отсчета времени или его окончания.

Так, приезжим, которые прибывают в Туву и пытаются действовать сообразно своим представлениям о пунктуальности, хронометраже, расписании, надо понимать, что специфичность региона выражается в том числе и в отношении местного населения ко времени. Сразу следует делать поправку на временной фактор и не ожидать соблюдения точных сроков, не требовать их, не провоцируя тем самым межкультурных конфликтов. Разумеется, не абсолютно всё столь сложно и непредсказуемо. Например, график работы определенных учреждений обязан строго соблюдаться. Но в местностях с малым количеством населения будет не удивительно, если даже официальные учреждения будут работать по тувинскому времени, то есть с сильным влиянием субъективных представлений о счастливых и несчастливых днях, о каких-то более важных делах и пр.

Жителям Тувы, которые выезжают из республики в другие регионы России, прежде всего в мегаполисы, а также за границу, приходиться обязательно перестраиваться для того, чтобы успевать, не опаздывать и не медлить с принятием решений. То есть тувинцам надо понимать, что тувинское время существует только на тувинской земле.

Я упомянула и жителей Тувы, имея в виду не только тувинцев, подчеркивая тем самым факт адаптации местного населения региона к тувинскому пониманию времени. Принятие ими этнокультурной особенности коренных жителей происходит практически неизбежно, особенно с учетом численного превосходства в республике тувинцев.

Перестройка на иное восприятие времени и принятие иной временной стратегии личных действий происходила и со мной лично, с автором данной статьи, поскольку я родилась и выросла в Туве, а с 1990-х годов уже постоянно проживаю и работаю в 
Москве. Тувинское время для меня «включается» лишь в момент приездов на малую Родину, когда приходится столичную пунктуальность отставлять и следовать здесь порой довольно непредсказуемому течению событий и встреч.

Органам власти (федеральной и региональной), выстраивающей стратегии экономического развития региона с учетом социального, культурного фактора, надо понимать, что «тувинское время» внесет коррективы со сдвигом сроков, создаст особую длительность согласований, добавит период ожидания «когда сверху скажут» и пр. Безусловно, это чрезвычайно неудобно с точки зрения и планирования, и отчетности, однако, к сожалению, так чаще всего и происходит.

Фактор тувинского времени очень важен для понимания немногочисленным представителям внешнего бизнеса, у которых появляется желание вести деловые переговоры с жителями Тувы прежде всего в самом регионе на месте и возможно планирующим открытие в республике производств, привлечение к нему местного населения в качестве наемных работников.

Например, завод сборки деталей, сложного технологического производства в Туве не запустить. Тувинцы просто не способны на монотонный, скрупулезно точный труд. Не потому, что не могут делать сложное и точное (вспомним народных умельцев, мастеров декоративно-прикладного искусства). А потому, что не приспособлены к монотонности и соблюдению точных хронометражей. Как показывают этносоциологические исследования, тувинцы сами предпочитают труд или животноводов, или творческий, то есть не жестко регламентированный.

\section{Заключение}

Тувинское время (тыва үе), которое удивляет, даже раздражает приезжих в Туве, в том числе и ученых - представителей других культур, представляет интереснейший аспект тувинской культуры, а шире - культуры номад центральной Азии. Это повседневный способ понимания времени, временной протяженности тувинцами, который восходит истоками в древние пласты культуры и представляется вполне оформленным способом постижения народом окружающего мира, пространственновременной основой картины мира. И в этом плане говорить о ненаучности знаний кочевников, их безграмотности и отсталости - это уже устаревший подход.

Будучи тесно связанным с хозяйственной деятельностью скотоводов, охотников, земледельцев - с экономической культурой, тувинское время было сформировано ее особенностями и в свою очередь обуславливало трудовую мотивацию, и оно до сих пор влияет на повседневное поведение значительной части населения. В советское время при наличии советских отношений доминирующий тип хозяйства сохранялся, поэтому, видимо, и проблема со временем не была столь острой для основной массы населения. И сейчас для тех, кто занят в традиционном хозяйстве, жизнь протекает по законам тыва үе.

Тувинское время стало проблемой, когда оно столкнулось с другим пониманием временем - представителей других культур. Сегодня, в условиях глобализации и тесного переплетения экономических интересов, влияния мирового рынка, наме- 
рений власти вывести регион на путь самообеспечения и социального развития, очевидно, что Тува должна, как и вся Россия, модернизироваться, т. е. осовремениваться. Но следует ли тогда считать, что тувинское время является препятствием в этом деле, особенно если мы определяем его как часть культурного сознания? Полагаю, что ответ на этот вопрос лежит в теме использования культурного багажа для модернизации, в сложной, но необходимой методике учета культурных факторов для постановки и решения экономических задач, особо значимых в горизонте стратегического планирования.

\section{СПИСОК ЛИТЕРАТУРЫ}

Айыжы, Е. В. (2015) Категория «возраст» и отношение к нему в традиционной культуре тувинцев // Казанский педагогический журнал. № 5-12. С. 415-421.

Балакина, Г. Ф., Анайбан 3. В. (1995) Современная Тува: социокультурные и этнические процессы. Новосибирск : Наука : Сиб. изд. фирма. 137 с.

Безуглова, Н. П. (2015) Культура как экономический феномен (зачем экономике нужна культура?) // Культура и образование. № 2. С. 33-44.

Бортникова, Т. Г. (2017) Отношение ко времени как отражение этнического сознания //Исторические,философские, политические июридические науки, культурология и искусствоведение. Вопросы теории и практики. № 5. С. 27-32.

Вайнштейн, С. И. (1972) Историческая этнография тувинцев. Проблемы кочевого хозяйства. М. : Наука. 314 с.

Волков Г. Н., Салчак К. Б., Шаалы А. С. (2009) Этнопедагогика тувинского народа. Кызыл : Тываполиграф. 212 с.

Жуковская Н. Л. (2002) Кочевники Монголии : Культура. Традиции. Символика. М. : Восточная литература. 247 с.

Кенин-Лопсан, М. Б. (2006) Традиционная культура тувинцев. Кызыл: Тувинское книжное издательство. 232 с.

Кононов, А. Н. (1978) Способы и термины определения стран света у тюркских народов // Тюркологический сборник. 1974. М. : Издательство «Восточная литература». 304 с. С. $72-89$.

Культура имеет значение. Каким образом ценности способствуют общественному прогрессу (2002) / под ред. Л. Харрисона, С. Хантингтона. М.: Московская школа политических исследований. 320 с.

Ламажаa, Ч. К. (2010) Тувиноведение: область знания и социальная миссия [Электронный ресурс] // Новые исследования Тувы. № 4. URL: https:/nit.tuva.asia/nit/ article/view/472 (дата обращения: 16.01.2018).

Льюис, Р. Д. (1999) Деловые культуры в международном бизнесе. От столкновения к взаимопониманию / пер. с англ. Т. А. Нестика. М. : Дело. 439 с.

Майский, И. М. (1959) Монголия накануне революции. М. : Изд-во восточной литературы. 309 с. 
Монгольский мир: между Востоком и Западом (2014) / под ред. Ю. В. Попкова, Ж. Амарсаны. Новосибирск : Автограф. 351 с.

Монгуш, Б. Б. (2015) Истоки двенадцатилетнего животного календаря и его связь с празднованием Шагаа [Электронный ресурс] // Новые исследования Тувы. № 1. URL: https://nit.tuva.asia/nit/article/view/50 (дата обращения: 01.02.2018).

Ондар, М. В. (2017) Стандарты, отражающие время в тувинских героических сказаниях // Филологические науки. Вопросы теории и практики. № 1. Ч. 2. С. 157-163.

Пространство в традиционной культуре монгольских народов (2008) /Нанзатов Б. 3., Николаева Д. А., Содномпилова М. М., Шагланова О. А. М. : Восточная литература. 341 с.

Потапов, Л. В. (1969) Очерки народного быта тувинцев. М. : Наука. 402 с.

Путешествие по северным берегам Сибири и по Ледовитому морю совершенное в 1820, 1821, 1822, 1823, и 1824 г.г. экспедицией под начальством флота лейтенанта Ф. П. Врангеля (1948) / под общ. ред. Е. Шведе. М. : Издательство Главсевморпути.

Скородумова, Л. Г. (2004) Монгольский язык: образы мира. Улан-Батор: б/и. 328 с.

Сузукей, В. Ю. (2009) Пространство и время в традиционной культуре тувинцев [Электронный ресурс] // Новые исследования Тувы. № 1-2. URL: https://nit.tuva.asia/ nit/article/view/669 (дата обращения: 09.02.2018).

Татаринцев, Б. И. (2002) Этимологический словарь тувинского языка. Новосибирск : Наука. Т. 2 (Д, Ё, И, Й). 388 с.

Традиционное мировоззрение тюрков Южной Сибири. Пространство и время. Вещный мир (1988) / Львова Э. Л., Октябрьская И. В., Сагалаев А. М., Усманова М. С. Новосибирск : Наука. 226 с.

Тувинско-русский словарь. Около 22 тысяч слов (1968) / под ред. Э. Р. Тенишева. М. : Издательство «Советская энциклопедия». 646 с.

Цыбульский, В. В. (1982) Календари и хронология стран мира. М. : Просвещение. $128 \mathrm{c}$.

Яковлев, В. М. Двенадцатилетний животный цикл в Китае и у древних тюрков [Электронный ресурс] // Синология.Py. URL: http://www.synologia.ru/a/ Двенадцатилетний\%20животный\%20цикл\%20в\%20Китае\%20и\%20у\%20древних\%20 тюрков (дата обращения: 09.02.2018).

Hall, E. T. (1966) The hidden dimension. Garden City ; New York : Doubleday. 201 p.

Hall, E. T. (1976) Beyond Culture. Garden City ; New York : Anchor Press. 256 p.

Lewis, R. D. (2006) When cultures collide: managing successfully across cultures. Boston ; London : Nicholas Brealey International. 599 p.

Sen, A. (2004) How Does Culture Matter? // Culture and Public Action / Rao, V. and Walton, M. (Hg.). Stanford : Stanford University Press. P. 37-58.

Дата поступления: 30.03.2018 г. 


\section{REFENECES}

Aiyzhy, E. V. (2015) Kategoriia «Vozrast» i otnoshenie k nemu v traditsionnoi kul'ture tuvintsev [Category of "Age" and the attitude of the Tuvans towards it in the traditional culture]. Kazanskii pedagogicheskii zhurnal, no. 5-12, pp. 415-421. (In Russ.).

Balakina, G. F. and Anaiban Z. V. (1995) Sovremennaia Tuva: sotsiokul'turnye i etnicheskie protsessy [Contemporary Tuva: socio-cultural and ethnic processes]. Novosibirsk, Nauka, Sib. izd. firma. 137 p. (In Russ.).

Bezuglova, N. P. (2015) Kul'tura kak ekonomicheskii fenomen (zachem ekonomike nuzhna kul'tura?) [Culture as an economic phenomenon: Why does the economy need culture?]. Kul'tura i obrazovanie, no. 2, pp. 33-44. (In Russ.).

Bortnikova, T. G. (2017) Otnoshenie ko vremeni kak otrazhenie etnicheskogo soznaniia [Attitude to time a reflection of ethnic consciousness]. Istoricheskie, filosofskie, politicheskie $i$ iuridicheskie nauki, kul'turologiia i iskusstvovedenie. Voprosy teorii i praktiki, no. 5, pp. 27-32. (In Russ.).

Vainshtein, S. I. (1972) Istoricheskaia etnografiia tuvintsev. Problemy kochevogo khoziaistva [Historical Ethnography of Tuvans. Problems of nomadic economy]. Moscow, Nauka Publ. 314 p. (In Russ.).

Volkov G. N., Salchak K. B. and Shaaly A. S. (2009) Etnopedagogika tuvinskogo naroda [The ethnopedagogy of the Tuvan people]. Kyzyl, Tyvapoligraf. 212 p. (In Russ.).

Zhukovskaia N. L. (2002) Kochevniki Mongolii : Kul'tura. Traditsii. Simvolika [Nomads Of Mongolia: Culture. Traditions. Symbolism]. Moscow, Vostochnaia literatura. 247 p. (In Russ.).

Kenin-Lopsan, M. B. (2006) Traditsionnaia kul'tura tuvintsev [Traditional Tuvan culture]. Kyzyl, Tuvinskoe knizhnoe izdatel'stvo. 232 p. (In Russ.).

Kononov, A. N. (1978) Sposoby i terminy opredeleniia stran sveta u tiurkskikh narodov [Methods and terms of finding cardinal directions among the Turkic peoples]. In: Tiurkologicheskii sbornik. 1974. Moscow, Vostochnaia literature Publ. 304 p. Pp. 72-89. (In Russ.).

Kul'tura imeet znachenie. Kakim obrazom tsennosti sposobstvuiut obshchestvennomu progressu [Culture Matters: How Values Shape Human Progress] (2002) / L. Harrison and S. Huntington (eds.), transl. from Engl. Moscow, Moskovskaia shkola politicheskikh issledovanii. 320 p. (In Russ.).

Lamazhaa, Ch. K. (2010) Tuvinovedenie: oblast' znaniia i sotsial'naia missiia [Tuvan studies as a field of knowledge and as a social mission]. The New Research of Tuva, no. 4 [online] Available at: https://nit.tuva.asia/nit/article/view/472 (access date: 16.01.2018). (In Russ.).

Lewis, R. D. (1999) Delovye kul'tury $v$ mezhdunarodnom biznese. Ot stolknoveniia $k$ vzaimoponimaniiu [Business Culture in International Business: from Collision to an Understanding] / transl. from Engl. by T. A. Nestik. Moscow, Delo. 439 p. (In Russ.).

Maiskii, I. M. (1959) Mongoliia nakanune revoliutsii [Mongolia on the brink of the revolution]. Moscow, Izd-vo vostochnoi literatury. 309 p. (In Russ.). 
Mongol'skii mir: mezhdu Vostokom i Zapadom [The Mongolian world: between East and West] (2014) / Iu. V. Popkov and Zh. Amarsany (eds). Novosibirsk, Avtograf. 351 p. (In Russ.).

Mongush, B. B. (2015) Istoki dvenadtsatiletnego zhivotnogo kalendaria i ego sviaz' s prazdnovaniem Shagaa [Origins of the 12-year animal calendar and its connection with the Shagaa festival]. The New Research of Tuva, no. 1 [online] Available at: https:/nit.tuva.asia/ nit/article/view/50 (access date: 01.02.2018). (In Russ.).

Ondar, M. V. (2017) Standarty, otrazhaiushchie vremia v tuvinskikh geroicheskikh skazaniiakh [Standards representing time in the Tuvinian heroic legends]. Filologicheskie nauki. Voprosy teorii i praktiki, no. 1, vol. 2, pp. 157-163. (In Russ.).

Potapov, L. V. (1969) Ocherki narodnogo byta tuvintsev [Essays on the traditional life of Tuvans]. Moscow, Nauka Publ. 402 p.

Prostranstvo $v$ traditsionnoi kul'ture mongol'skikh narodov [Space in the traditional culture of the Mongolian peoples] (2008) / Nanzatov B. Z., Nikolaeva D. A., Sodnompilova M. M. and Shaglanova O. A. Moscow, Vostochnaia literatura. 341 p. (In Russ.).

Puteshestvie po severnym beregam Sibiri i po Ledovitomu moriu sovershennoe v 1820, 1821, 1822, 1823, i 1824 g.g. ekspeditsiei pod nachal'stvom flota leitenanta F. P. Vrangelia (1948) [The journey along the Northern shores of Siberia and the Arctic sea made in 1820, 1821, 1822, 1823, and 1824 by the expedition under the command of Navy Lieutenant F. P. Wrangel] / ed. by E. Shvede. Moscow, Izdatel'stvo Glavsevmorputi. (In Russ.).

Skorodumova, L. G. (2004) Mongol'skii iazyk: obrazy mira [Mongolian language: images of the world]. Ulan-Bator, s.n. 328 p. (In Russ.).

Suzukei, V. Iu. (2009) Prostranstvo i vremia v traditsionnoi kul'ture tuvintsev [Space and time in traditional Tuvan culture]. The New Research of Tuva, no. 1-2 [online] Available: https://nit.tuva.asia/nit/article/view/669 (access date: 09.02.2018). (In Russ.).

Tatarintsev, B. I. (2002) Etimologicheskii slovar' tuvinskogo iazyka [An etymological dictionary of the Tuvan language]. Novosibirsk, Nauka. Vol. 2 (Д, Ё, И, Й). 388 p. (In Russ.).

Traditsionnoe mirovozzrenie tiurkov Iuzhnoi Sibiri. Prostranstvo i vremia. Veshchnyi mir [The traditional worldview of Turkic peoples of South Siberia. Space and time. The outer world] (1988) / ed. by L'vova E. L., Oktiabr'skaia I. V., Sagalaev A. M. and Usmanova M. S. Novosibirsk : Nauka. 226 s.

Tuvinsko-russkii slovar'. Okolo 22 tysiach slov [A Tuvan-Russian dictionary. C. 20,000 words] (1968) / ed. by E. R. Tenishev. Moscow, Sovetskaia entsiklopediia Publ. 646 p. (In Russ.).

Tsybul'skii, V. V. (1982) Kalendari i khronologiia stran mira [Calendars and chronology of the world]. Moscow, Prosveshchenie. 128 p. (In Russ.).

Iakovlev, V. M. Dvenadtsatiletnii zhivotnyi tsikl v Kitae i u drevnikh tiurkov [The twelveyear animal cycle in China and among ancient Turks]. Sinologiia.Ru [online] Available at: http://www.synologia.ru/a/Dvenadtsatiletnii\%20zhivotnyi\%20tsikl\%20v\%20Kitae\%20 i\%20u\%20drevnikh\%20tiurkov (access date: 09.02.2018). (In Russ.).

Hall, E. T. (1966) The hidden dimension. Garden City, New York, Doubleday. 201 p.

Hall, E. T. (1976) Beyond Culture. Garden City, New York, Anchor Press. 256 p. 
Lewis, R. D. (2006) When cultures collide: managing successfully across cultures. Boston; London: Nicholas Brealey International. $599 \mathrm{p}$.

Sen, A. (2004) How Does Culture Matter? In: Culture and Public Action / Rao, V. and Walton, M. (Hg.). Stanford, Stanford University Press. Pp. 37-58.

Submission date: 30.03 .2018$.

\section{Для цитирования:}

Ламажаа Ч. К. Тувинское время и экономическая культура тувинцев [Электронный ресурс] // Новые исследования Тувы. 2018, № 2. URL: https://nit.tuva.asia/nit/ article/view/768 (дата обращения: дд.мм.гг.). DOI: 10.25178/nit.2018.2.1

\section{For citation:}

Lamazhaa Ch. K. "Tuvan time” and economic culture of Tuvans. The New Research of Tuva, 2018, no. 2 [on-line] Available at: https://nit.tuva.asia/nit/article/view/768 (accessed: ...). DOI: 10.25178/nit.2018.2.1 